\title{
A super 'lead pipe' colon: radio-pathological correlation of long-standing ulcerative colitis
}

\section{A Weinstein, MB ChB, FCR (D) SA, FRCR} (Lond)

Witwatersrand Group of Teaching Hospitals, Departments of Radiology, Helen Joseph and Coronation Hospitals, Johannesburg

M Gritzman, MB ChB, FFPath (SA)

I van Niekerk, MB ChB, FC Path (SA)

Gritzman \& Thatcher Laboratories, Johannesburg

B Bebington, MB ChB, FCS (SA)

Donald Gordon Medical Centre, Johannesburg

\section{Introduction}

This report demonstrates the progression of a defunctioned colon in a patient with ulcerative colitis (UC), 20 years after ileostomy without colectomy. Long-segment stricture formation in UC is a more intensive local manifestation of a process involving the entire thickness of the wall of the bowel.

\section{Case report}

A 59-year-old woman presented with a pink watery anal discharge. She had undergone a diverting end-ileostomy for ulcerative colitis 20 years previously. It is not clear why a colectomy was not done; possibly she had been too ill for extensive surgery, and thereafter was content with the outcome. She also had progressive pyoderma gangrenosum around the skin of the stoma. The ileostomy was functioning normally, and she had not been on steroids. She had a normal C-reactive protein, and no leukocytosis. Stool culture showed normal flora.

At endoscopy, a small inflamed rectum with minute calibre of the more proximal bowel was seen, too narrow to proceed further. The plain film showed no thumbprinting or mural gas. A water-soluble enema (Fig. 1) demonstrated a complete colon of minute calibre - a real 'lead pipe' colon! Total proctocolectomy was performed; an ileo-anal pouch anastomosis was not recommended in view of the patient's age and possible further complications. ${ }^{1}$ Postoperative recovery was uneventful.

Histological examination revealed a florid acute(!) ulcerative colitis. The bowel was narrowed, with areas of stricture formation and marked bowel wall thickening (Fig. 2). Extensive mucosal ulceration with underlying inflamed granulation tissue was noted. The remainder of the non-ulcerated mucosa showed acute-on-chronic inflammatory cell infiltration with crypt-abscess formation, distorted glandular architecture, regenerative changes and gland loss (Fig. 3). No dysplasia or malignancy was seen. There was marked submucosal fat infiltration (Fig. 3).

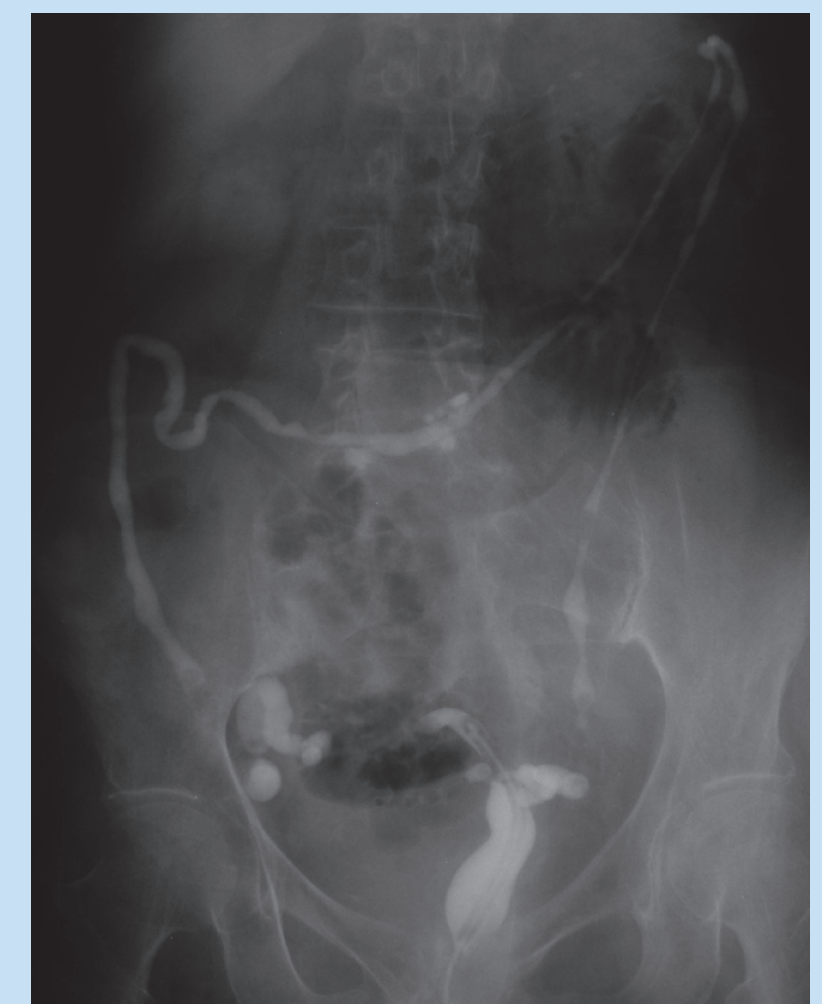

Fig. 1. Water-soluble enema demonstrating a super 'lead pipe' colon.

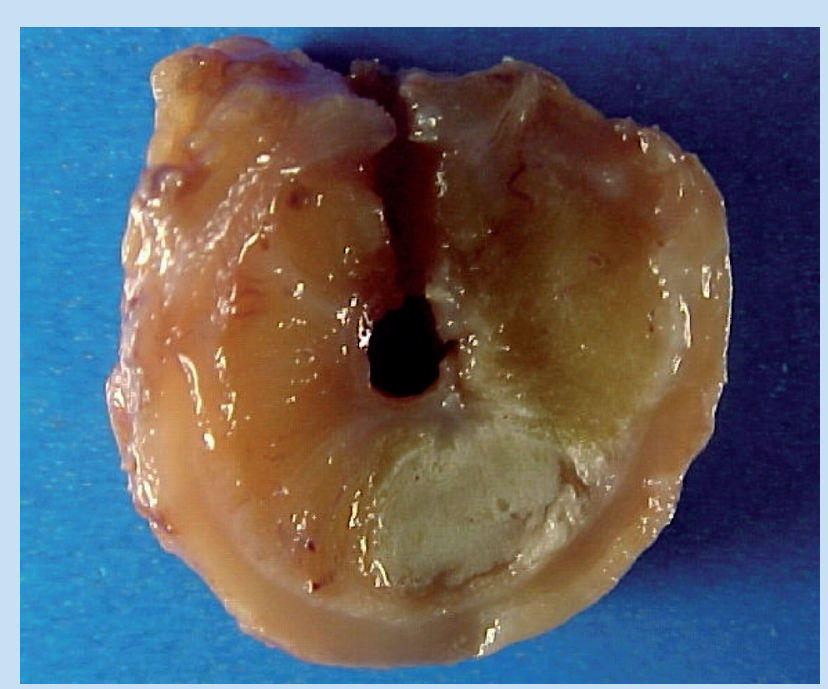

Fig. 2. Cross-section of the colon demonstrating massive submucosal adipose deposition and minute calibre of the lumen. 


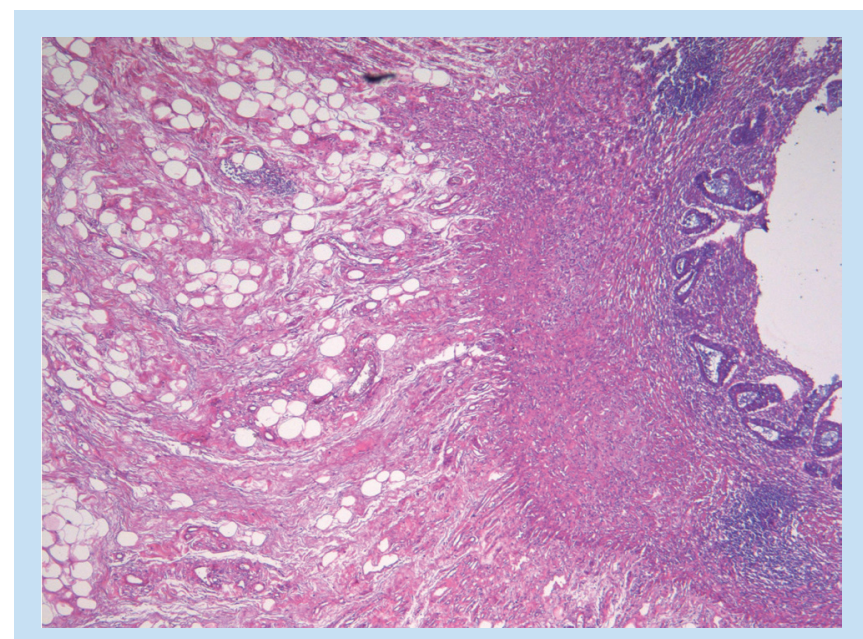

Fig. 3. Microscopy of colonic mucosa demonstrating acute-on-chronic inflammatory infiltrate and submucosal adipose deposition.

\section{Discussion}

Benign strictures in ulcerative colitis are said to occur in up to $11 \%$ of cases. $^{2}$ This case demonstrates that longstanding UC does not affect only the mucosa. In the chronic phase, wall thickening, marked loss of haustration and colonic shortening can also occur.

Fibrosis was minimal and insufficient to account for stricturing, as previously assumed, and is mostly the result of hypertrophy and thickening of the muscularis mucosa, as in our case (Fig. 3). In addition, contraction causing partial separation of the inner and outer layers of the muscularis mucosa added to the thickening. The mechanism by which this occurs in a disease regarded primarily as mucosal is unclear. In Goulston and McGovern's study ${ }^{3}$ of 436 chronic UC patients, where 156 were operated on, 19 had reduction of lumen calibre by two-thirds. They found that ' ... strictures appeared only when the disease ran a continuous course without remission and only when the disease was present for more than five years'. In our case, the disease had been present for $>20$ years.

Loss of haustration is not unique to UC; it also occurs in Crohn's colitis, cathartic colon, diversion colitis, dysenteries, tuberculous strictures, progressive systemic sclerosis and amyloid infiltration.

In Crohn's colitis, hypertrophy of the muscularis mucosa is also found but, in contradistinction to UC, the entire bowel wall is inflamed and areas of fibrosis extend to the serosa. Submucosal fat deposition (present in this case) has been described as giving the 'target' sign on computed tomography (CT) in both UC and Crohn's colitis, ${ }^{4}$ although this occurs more frequently in UC. ${ }^{5}$ The cause is unknown, although there may be a link to steroid therapy; our patient had not been on steroids for years, and probably had pancolitis from the onset.
In a clinicopathological study of 21 cases of diversion colitis, $\mathrm{Ma}$ et al. ${ }^{6}$ found mostly nonspecific changes such as inflammatory cell infiltrates in the lamina propria, but there were no consistent patterns, and certainly none of the characteristic features of UC. Re-anastomosis restores the affected bowel.

Malignant transformation (dysplasia) is mostly not apparent on radiological screening. Colonoscopy with multiple random biopsies ${ }^{7}$ is the surveillance method of choice - clearly not possible in our case. Strictures should be considered cancerous until disproven histologically.

Curiously, contrast enemas are only moderately sensitive, ${ }^{8}$ with detection rates of $70 \%$, and a preliminary accurate diagnosis of cancer of only $40 \%$. This marked disparity compared with detection rates in non-UC cancer is due to the annular infiltrative insidious growth of these tumours, as well as to pre-existing colonic distortion from the inflammatory process. James and Carlson ${ }^{9}$ found that $65 \%$ of the cancers in UC had an infiltrative pattern as opposed to the familiar 'apple core' in non-UC cancer cases, which highlights the need to regard minimal fixed-calibre change on contrast enemas with suspicion. Ekbom et al. ${ }^{10}$ emphasised that the extent of colitis at diagnosis and age at diagnosis are strong independent determinants for an increase in the relative risk of cancer in UC.

Clearly, correct diagnosis is crucial. Our case not only had severe findings and a diagnosis that predated her surgery, but also had no clinical, radiological or histological features of the other alternative diagnoses. The case demonstrates an unusually severe form of 'lead pipe' colon occurring in a large bowel with persistent active disease despite long-term diversion.

The authors thank Professor J Oettle for his assistance and input.

1. Cima R, Pemberton JH. Medical and surgical management of chronic ulcerative colitis. Arch Surg 2005; 140: 300-310.

2. de Dombal FT, Watts JM, Watkinson G, Goligher JC. Local complications of ulcerative colitis: stricture, pseudopolyposis and carcinoma of the colon and rectum. BMJ 1966; 1: 1442-1447.

3. Goulston SJM, McGovern VJ. The nature of benign strictures in ulcerative colitis. New Engl J Med 1969; 281: 290-295.

4. Jones B, Fishman EK, Hamilton SR, et al. Submucosal accumulation of fat in inflammatory bowel disease: CT/pathological correlation. J Comput Assist Tomogr 1986; 10: 759-763.

5. Philpotts LE, Heiken JP, Westcott MA, Gore RM. Colitis: Use of CT findings in differential diagnosis. Radiology 1994; 190: 445-449.

6. Ma CK, Gottlieb C, Haas PA. Diversion colitis: a clinicopathologic study of 21 cases. Hum Pathol 1990; 21: $429-436$.

7. Stevenson GW, Goodacre R, Jackson R, Ragbeer M, Rowland R. Dysplasia to carcinoma transformation in ulcerative colitis. Am J Roentgenol 1984; 143: 108-110.

8. Fennessy JJ, Sparber MB, Kirsner JB. Radiological findings in carcinoma of the colon complicating chronic ulcerative colitis. Gut 1968; 9: 388-397.

9. James EM, Carlson HC. Chronic ulcerative colitis and colon cancer: Can radiographic appearance predict survival patterns? Am J Roentgenol 1978; 130: 825-830.

10. Ekbom A, Helmick C, Zack M, Adami H-O. Ulcerative colitis and colorectal cancer: A population-based study. New Engl J Med 1990; 323: 1228-1233. 